By RALPH R. SHAW

\title{
The Publication Board
}

\begin{abstract}
$A$ FTER World War I entirely new indus1 tries, such as radio, sprang from waraccelerated research. Other industries, such as the manufacture of automobiles, were brought to maturity by war needs and war-related developments.
\end{abstract}

The scientific developments during the current war dwarf those of past centuries. Few of us doubt that the source of "jobs for all," if it is to be found anywhere, will be in the prodigious store of useful knowledge developed during the last five years under the stress of emergency conditions.

This reservoir of "jobs for all" is dammed up by the walls of secrecy which have, by necessity, been built up around scientific and technical developments of our country during the war years. Within this great reservoir of scientific and technical knowledge are the molecules (or dare we say atoms?) from which new industries may spring. Alongside this reservoir of secrecy is another one, whose walls are fashioned from the rubble of war-shattered communications, controlled by a complex system of dams which stop the flow of secret technical developments of other countries and of enemy information captured by our armies and our allies.

In order to release materials from these reservoirs, the President issued Executive Order No. 9568 on June 8, 1945, providing for the release of scientific and technical information which has been, or may hereafter be developed by, or for, or with the funds of, any department or agency of the government and which is classified. ${ }^{1}$

\footnotetext{
1 "Classified" as used in this paper refers to designation of a publication or report as restricted, confidential, secret, etc., within the meaning of the war secrets act.
}

This executive order established a publication board, which consists of the Director of War Mobilization and Reconversion, the Attorney-General, the Secretary of the Interior, the Secretary of Agriculture, the Secretary of Commerce, and the Secretary of Labor. The board operates in the Department of Commerce under John C. Green as executive secretary.

Having provided the mechanism for speedy selective flow of scientific and technical data originating in the United States, the President issued Executive Order 9604 on Aug. 25, 1945, which provided for the release of captured enemy scientific and technical data and for the release of data obtained from our allies.

The general problem faced by the publication board and by librarians is that of making scientific and industrial information available to industry. Its job is to "provide for the release for publication by individuals or groups, insofar as it may be done without prejudice to the public interest, of certain scientific and technical data now or hereafter withheld from public dissemination for the purpose of national military security, to the end that such information may be of maximum benefit to the country."

It might be well to note some of the things with which the publication board is not concerned:

First, the publication board is not concerned with material which is not classified, i.e., is now freely available. The publication board will not act as a censor of government or private publishing, but will do everything in its power to encourage the most widespread dissemination of information which does not involve considerations of the national security. 
Second, the publication board will not itself reproduce the bulk of the material which it is declassifying, but rather will encourage its publication or photoduplication by other agencies.

Third, the publication board will not establish a library to service these materials, but rather will make use of existing libraries in order to avoid the meticulous and time-consuming operations which are involved in making a document or a book a part of a permanent library collection.

Fourth, the publication board does not now exercise final authority over what may be obtained from enemy sources, since that is still, in large measure, within the control of the armed forces and in some cases may be subject to international agreement. The board can only declassify and disseminate what is delivered to it from the sources which are in control of the original materials. Unfortunately, some of this material is in very poor condition, owing to difficulties in making copies in the field, but it is all that is available.

The total number of documents or publications involved in this project is unknown. However, it has been estimated, on the basis of the available information, that tens of thousands of tons of reports and publications are involved. Just how many thousands of tons are involved is open to conjecture.

One of our first reactions when faced with tremendous masses of literature is to ask "Why not microfilm it?" We are accustomed to handling considerable masses of material on microfilm, but when we are faced with the above quantity of material, the mechanical job of microfilming assumes uneconomic proportions. Microfilming of a single lot of ten thousand tons of material would require at least one hundred camera teams and developing-room teams for more than fifty years, and that figure would have to be multiplied by $x$ lots of that size to get the total. The number of rolls of film involved would mount into the millions, and each roll would have to be indexed in detail to make its contents findable.

\section{Method of Operation}

Faced by a job of this magnitude, it appeared that the only sound method of operation would be to mobilize all of the interested forces in the government and in the country as a team to provide for selective declassification and dissemination of the more important materials at the highest rate of speed consistent with efficient operation. To achieve this end it was decided first that abstracting and indexing would be made the responsibility of interested, nonprofit, scholarly groups so far as possible. Such groups as the American Chemical Society are accustomed to disseminating knowledge contained in literature to their membership and to people interested in chemistry at large.

A number of government agencies and other organizations are willing to aid in this program in order to fulfil their own primary functions, which include the dissemination of knowledge. The work of the board is so designed as to make maximum use of all cooperating bodies and it welcomes offers of cooperation from any group which can carry responsibilities for abstracting and disseminating knowledge on a nonprofit basis.

The problems faced by the board are those of declassification and dissemination or publication.

\section{Declassification}

Materials are submitted to the board either because of need for declassification of a particular item or in accordance with the board's instructions to all agencies that they submit all classified material to the board with their recommendations for declassification. Some material will be obtained from our allies by exchange arrangements.

Upon receipt by the publication board each document is numbered and filed in the custody section pending declassification. 
The board considers the recommendations of the agencies submitting material for declassification and, in cooperation with the Army and the Navy, determines whether or not the publication may be declassified.

\section{Publication}

The concept of publication under which the board operates is the broad concept of "announcing or making known" rather than the narrower concept of printing and distribution of multiple copies. It would, obviously, be impossible to set up in type and to print all of the material which will pass through the hands of the publication board. Large numbers of these reports will be of such highly specialized character that there will not be enough demand for them to justify printing or even mimeographing. Others have been produced by federal agencies which plan to publish them as part of their normal responsibilities. The publication board encourages the printing or mimeographing and distribution of declassified material by their issuing bodies or by other interested groups. At present the reproduction program of the publication board is limited to between five hundred and one thousand combined intelligence objective surveys and similar "target investigations" made by groups of specialists under Army and Navy supervision.

Publication, in the sense used by the board, will be, for the great mass of material, the act of announcing it publicly and placing it in libraries where it can be used by the public, either for direct reference or in microfilm and photostat copies.

Thus, normally, when a publication is declassified the library group in the publication board will prepare an entry for the publication and will add to the entry an abstract or note which it may itself prepare or which may come with the publication. In some cases cooperating agencies will pre- pare the abstracts and disseminate them. Generally, however, the abstracts prepared in the library section of the publication board will be printed in a weekly bulletin and made generally available.

The publication itself will then be sent to the cooperating library covering its subject-matter field. Initially the cooperating libraries are Library of Congress, Army Medical Library, and the Department of Agriculture Library. One or two other government libraries may be added to the list. These libraries will' file the publications by the number assigned to them by the publication board.

The abstract will give the price for a microfilm or photostat, requesting that all orders be sent to the publication board by number. When the orders are received by the board the copy requested will be obtained from the library in which the publication is housed and will be supplied to the person requesting it, at the cost of making the copy.

In the limited number of cases in which the publication board does mimeograph a report, it provides copies for free distribution to the all-depository libraries and to government agencies. There will be no copies available for free distribution above this number, and all copies required. by other libraries, institutions, or business establishments will be provided at the cost of producing them.

As a further means of disseminating government publications which were formerly classified, the board has encouraged federal agencies which have multiple copies of such publications to send I 30 copies of each, when they are available, to the Library of Congress, which has arranged for their distribution to the all-depository libraries through the Government Printing Office. More than four hundred publications were sent to all-depositories under this arrange- 
ment by the middle of December 1945 .

The weekly abstract bulletin will be made available to depository libraries. Others may subscribe to it through the Superintendent of Documents.

In its present state this material is comparable in size to one of our great research collections, but it is scattered all over the country and over half the world in boxes, bundles, files, caves, and possibly even in the inevitable salt mines. Most of it is available in manuscript form only, or in a single, poor, microfilm copy. There is no catalog of this material nor has it been organized, so that no one really knows what is available or where it may be.

Obviously, a large portion of our own classified or enemy reports is of little value for practical industrial application in the immediate future. A large portion of it may be worthless. The publication board's job is that of acquiring material as rapidly as possible and organizing it so that final selection may be made by those who will apply this knowledge to the industrial and economic benefit of the country.

One of the important tools which will develop from the operations of the library unit of the board will be a master subject card index which will eventually provide a guide to the knowledge contained in this great mass of scientific and technical literature.

The responsibility of the librarians employed by the board to organize this material is a heavy one, but still greater is the responsibility of the librarians of research, industrial, and other special libraries who will, in the final analysis, be responsible for making the truly important and immediately applicable information available to their own organizations.

\section{The Department of State and Acquisition of Foreign Materials}

\section{(Continued from page 104)}

government, the transcendent importance of such materials in day-to-day federal operations. Moreover, the department has recognized the principle that certain private collections of such material are of national importance, although they are not and should not be duplicated in Washington, and has consequently held that department assistance may be given these collections in their procurement problems under certain circumstances.

It is hoped and expected that the techniques embraced by this expanded program will greatly benefit those responsible for the conduct of the public business. It is also hoped that material assistance can, where it is justified, be given to private institutions. The private institutions must regard seriously, however, their responsibility so to correlate their several acquisitions needs that, when assistance is requested in a given area, an integrated program can be presented to the department by the libraries. The department hopes that such coordination within the government can be achieved through the efforts of the interdepartmental committee. It must have a similar background against which to work when it undertakes to aid nongovernmental research institutions. 